\title{
A LUTA CONTRA A AIDS: UMA CAUSA, MÚLTIPLOS SABERES
}

\author{
THE FIGHT AGAINST SIDA: \\ A CAUSE, MULTIPLE KNOWLEDGE
}

Fernanda Rios Petrarca*

A Aids, considerada por órgãos internacionais, como a OMS (Organização Mundial da Saúde), um dos maiores problemas de saúde pública mundial, atingiu proporções devastadoras que superaram outras epidemias, tais como a sífilis no final do século XIX e a tuberculose no início do século XX. De início ela colocou em cena um conjunto diverso de atores, dentre os quais se destacaram os especialistas (médicos, cientistas, pesquisadores), os ativistas (lideranças do movimento homossexual) e os grupos dos portadores do vírus. Estes atores adquiriram um papel fundamental, destacando-se na mobilização em torno da doença e na sua definição enquanto um problema público.

Diante disso, este artigo analisa, mais especificamente, como no processo de formação de uma coletividade em torno da problemática da Aids, no cenário nacional brasileiro, ativistas e especialistas se manifestaram na defınição da doença e nas suas formas de tratamento. Partimos do princípio que nesse processo estes atores expressaram opiniões, discutiram, julgaram, entraram em polêmicas, além de estabelecerem contatos, mobilizarem os já constituídos e instituírem novos vínculos, contribuindo para a formação de uma arena pública em torno do assunto ${ }^{1}$.

Um dos problemas centrais que tem sido colocado neste tipo de pesquisa, diz respeito à relação entre os saberes dos especialistas, obtidos pela inserção profissional, e os saberes dos ativistas obtidos pela inserção na esfera da política, como associações, movimentos e grupos. Mais do que concorrenciais, o que alguns estudos têm demonstrado

\footnotetext{
* É doutora em sociologia, professora e pesquisadora do Programa de Pós-graduação em Sociologia e do Programa de Pós-graduação em Comunicação (UFS, Aracajú/SE), é bolsista produtividade do CNPq e coordenadora o Laboratório de Estudos do Poder e da Política (LEPP/UFS). f.petrarca@uol.com.br.

1. Segundo Cefai (2002), as arenas públicas se formam em torno do problema e como parte dele, e envolvem as redes dos atores individuais, suas competências e performances, contribuindo para conectar os diferentes mundos sociais.
} 
é a intensa imbricação e complementaridade entre estes saberes ${ }^{2}$. Portanto, as pesquisas recentes têm se aproximado de uma análise das múltiplas competências e da associação de determinadas esferas. De forma mais específica, não é a oposição entre especialistas e ativistas que permite compreender a construção das causas, mas a forma como os profissionais, que atuam na defesa de causas, são conduzidos a fazer uso de dois "registros de legitimação" - para usar aqui uma expressão de Lochard e Simonet (2009), que são as competências profissionais e a ação política. Trata-se do peso que exerce a multiposicionalidade, o multipertencimento, e as trajetórias e carreiras que se formam em diferentes universos. Assim, a figura do profissional engajado se constitui na circulação entre o espaço profissional e o engajamento político, entre a profissão, as associações militantes e as instituições públicas. Esta múltipla inserção exerce um papel importante nos processos de reelaboração da imagem do profissional e do sentido atribuído ao conhecimento especializado.

Sendo assim, uma série de procedimentos analíticos se apresenta para pensar a relação entre saberes profissionais e saberes políticos na construção de uma causa pública. Dentre eles está o exame do contexto no qual estão inseridos os atores e sua importância para produção de significados. Portanto, os tipos de atores que investem na causa da Aids, assim como em outras causas sociais, não são defınidos por características a priori (passado político, percurso profissional, origens sociais, etc.), mas eles se constituem no curso das suas intervenções públicas e nos contextos de interação nos quais se engajam. Dito de outro modo, para entender que tipo de profissional e ativista investe na luta contra a Aids, é preciso analisar a conjuntura na qual a causa emerge.

Como bem já frisou Becker (2007), o entendimento das pré-condições não significa que um fato determinado acontecerá ou que um engajamento ocorrerá. Os atores agem com base nas situações que se apresentam e são elas que geram novas possibilidades de ação. Nesse sentido, é uma sequência de eventos, situações e fatos que aproximam profissionais, ativistas, grupo dos portados do HIV, tornando possivel o acionamento das redes de relações das quais fazem parte, e contribuindo para que suas experiências e competências sejam mobilizadas ${ }^{3}$.

As redes são entendidas, neste trabalho, como o conjunto de laços sociais que os indivíduos criam e mobilizam e que estão diretamente associados a certos espaços de socialização e ao contexto. Tais redes se desenvolvem com o tempo e dependem das situações, uma vez que são elas que permitem acionar laços anteriormente estabelecidos ou constituir novos vínculos. Partimos aqui de uma literatura ${ }^{4}$ que tem apontado o papel das redes nos processos de recrutamento

2. Dentre estes estudos podemos citar: Petrarca (2007) que destaca os espaços sociais em que se inserem os jornalistas e que contribuem para apreensão de saberes que podem ser mobilizados para o jornalismo; Lochard \& Simonet-Cusset (2003), sobre a forma como a vida associativa e a participação em organizações fornecem condições para uma "expertise coletiva”; e Epstein (1996), que destaca como o ativismo da Aids e a agenda dos ativistas se tornaram essenciais para a constituição de uma "ciência da Aids".

3. Uma análise mais detalhada e aprofundada sobre a definição da situação pode ser encontrada em Fornel, M. \&t Quéré, L. (1999).

4. Sobre esta literatura ver especialmente Passy e Guiuni (2001) e Snow, Ekland-Olso e Zurcker Jr. (1980). 
dos ativistas e sua múltipla função. Além de socializar, as redes oferecem, por um lado, possibilidades de participação contribuindo para formação de visões de mundo e concepções que podem ser mobilizadas para compreensão das causas; por outro lado, as redes formam o espaço de defınição pública de um problema. Em outras palavras, elas formam a arena de debate.

A contribuição principal deste texto é demonstrar, a partir do caso da luta contra a Aids, que determinadas categorias como "profissional" e "ativistas" não devem ser pensadas como monolíticas ou invariantes, ou como categorias, por definição, conflitantes. Mas ao contrário, deve-se procurar demonstrar como elas se articulam, interagem uma sobre a outra e se constrangem mutuamente. Uma das maneiras de demonstrar empiricamente, isso que estamos querendo dizer, é por meio da análise da dinâmica de construção pública da Aids considerando para tanto: o contexto, as situações ou eventos e redes de relações que aproximam ativistas e profissionais. Estamos mais atentos, portanto, aos mecanismos de construção da causa, e como a "lógica da situação" fornece os elementos fundamentais para compreender a formação e o acionamento das redes que unem ativistas e especialistas.

Este trabalho resulta de uma pesquisa mais ampla ${ }^{5}$ sobre a relação entre dinâmicas de atuação profissional e engajamento na defesa de causas sociais em Aracaju. A luta contra a Aids não desponta como uma das principais causas nesta referida pesquisa, uma vez que ela está inserida em movimentos e organizações que têm como foco outros temas, como o combate à homofobia, defesa dos direitos dos homossexuais, defesa do direito à saúde. Nesse sentido, são poucas as associações em Sergipe que têm como bandeira a luta contra a Aids, o que faz com que se torne um tema, dentre outros, das organizações. Este dado vai ao encontro de uma recente pesquisa, a nível nacional, realizada pela Associação Brasileira de Organizações não Governamentais (ABONG), a qual demonstrou que $6,8 \%$ das associações têm como principal bandeira a luta contra as DSTs e a Aids. A luta contra a Aids não constitui a pauta central das associações não governamentais e os portadores do vírus da Aids formam apenas 2,7\% dos sujeitos a quem estas lutas se destinam.

Contudo, apesar da mobilização contra a Aids não representar uma causa em destaque, do ponto de vista estatístico ela se tornou, ao longo da pesquisa citada, um caso particular de articulação entre ativistas (lideranças do movimento homossexual), especialistas (médicos sanitaristas) e grupo dos portadores do vírus. 0 exame da construção da Aids no cenário nacional nos permitiu identificar que a especificidade desta causa está na sua diversidade interna, uma vez que ela agrega ativistas com características diferenciadas e envolve uma pluralidade de saberes e redes. Além disso, as principais organizações de combate à doença são caracterizadas pela forte profıssionalização dos serviços.

Partimos, portanto, da análise da dinâmica de construção da Aids enquanto um problema social no cenário nacional, ou seja, do exame da carreira do problema, seu percurso e etapas de definição. A análise da

5. Esta pesquisa, denominada “Atuação profissional e defesa de causas” (PETRARCA, 2012), contou com o financiamento do CNPq, a quem agradecemos por nos possibilitar as condições necessárias para o desenvolvimento da pesquisa. 
carreira do problema nos permite compreender, de um lado, os contextos e as situações que criam possibilidades de engajamento e fazem emergir um conjunto de atores que passam a investir na luta contra a doença e, de outro lado, contribui para apreensão das redes de relações que os atores estão inseridos. As fases constitutivas da carreira do problema são caracterizadas por processos e dinâmicas próprias, assim como pela distribuição de atores. Em um texto clássico sobre sociologia pragmática dos problemas sociais, Spector e Kitsuse ${ }^{6}$ (2012) destacam que são os diferentes fatores que condicionam o desenvolvimento de um problema e a passagem de uma fase para outra.

A construção de uma situação como problemática envolve um processo de definição coletiva e resulta do trabalho de grupos na identificação, elaboração do problema e constituição de novos coletivos (LENOIR, 1998). Assim, para a causa da Aids emergir como um problema público foi preciso que um conjunto de atores, advindos de espaços diversificados, identificassem a situação como problemática e, em torno da aproximação com a causa da Aids e do investimento na elaboração desta situação, contribuíssem para fazer surgir novos grupos. Um dos principais desafios metodológicos consiste em apreender tanto a lógica das situações - por meio do exame da dinâmica de construção do problema quanto o passado do ator, uma vez que "as situações têm uma lógica própria que se impõem aos agentes, mas igualmente esses mesmos agentes não se engajam em uma situação desprovidos de toda experiência" (MATHIEU, 2012, p. 227).

\section{A Construção Social de uma Causa: a Síndrome da Imunodeficiência Adquirida}

A análise da carreira de um problema social e o processo que leva a uma situação qualquer ser definida e caracterizada como um problema de ordem pública, passa por diferentes fases, como sugerem, desde os autores que fizeram estudos inaugurais nesta temática (BLUMER, 1971; SPECTOR \&t KITSUSE, 2012) até os mais contemporâneos (CEFAÏ, 1996; LENOIR, 1998). Tais fases dependem do contexto histórico e geográfico, uma vez que a gênese de constituição não é a mesma para todas as carreiras de problemas públicos. Dependendo das condições históricas especificas, certas etapas podem não aparecer, e outras, apresentadas como sucessivas, se manifestam ao mesmo tempo.

Nesse trabalho caracterizamos três fases distintas. A primeira fase corresponde à emergência do problema e à formação de grupos: esta é a fase da conversão das dificuldades de ordem particular e privada em problemas públicos, em que os protagonistas são designados e se difundem discursos sobre a definição do problema. A segunda corresponde à formulação de reivindicações dentro de um espaço de discussão pública: este é o momento de institucionalização do problema em que ele passa a constar na agenda de preocupações do Estado; esta institucionalização coloca em evidência a participação dos atores coletivos em agências administrativas e poderes públicos. E, por fim, a terceira fase, corresponde à emergência do ativismo Aids e sua conexão com a cristalização de um espaço institucional fortemente marcado pela presença do Estado.

6. Este texto foi originalmente publicado em 1973 e recentemente traduzido para o francês por Cefai $\mathrm{Ct}$ Terzi (2012). 
Cada uma destas fases corresponde a situações específicas e a um conjunto diversificado de atores e redes envolvidos. Assim, é na relação entre as condições situacionais, as lógicas temporais e as configurações dramáticas da atividade coletiva que os atores se constituem, investem, se engajam e se comprometem na luta contra a doença. Nesse processo, eles mobilizam os saberes obtidos em outros domínios, as redes de relações acumuladas e os grupos de afınidade dos quais fazem parte. Uma análise, portanto, da constituição de um problema social precisa articular tanto as situações e suas configurações, quanto o passado dos atores.

\subsection{De "mal de folhetim" a mobilização coletiva}

A luta contra a Aids no Brasil, no que diz respeito a grupos organizados que se manifestaram em torno da doença, emerge em meados dos anos 1980 e tem como referência, assim como em outros países, o aparecimento de casos da doença. As mobilizações, manifestações e pressões realizadas por diferentes setores da sociedade despontam no cenário nacional com a divulgação dos primeiros casos de contaminação, sobretudo em brasileiros que haviam viajado para o exterior, em especial os Estados Unidos. Um dos casos mais midiáticos, neste momento, foi o do estilista Marcos Vinícius Resende Gonçalves, conhecido como Markito. A divulgação da sua contaminação apontava o começo da epidemia no Brasil.
Contudo, antes mesmo do aparecimento dos primeiros casos, a Aids já era noticiada e considerada como um tema de discussão pública, o que segundo alguns autores (CARRARA; MORAES, 1985; GALVÃO, 1992) a tornava um "mal de folhetim". Esta primeira fase de construção da Aids como uma problema social, e que traz a mídia como um ator central, desempenha um papel importante na circulação e difusão do que estava sendo produzido sobre a doença e das consequentes reações a ela. Este é o momento em que se toma consciência do problema no país, por meio da identificação dos primeiros casos mundiais e da resposta que os países estavam dando à doença.

Portanto, sem casos para examinar e sem um corpo médico que se confrontasse com a doença e formulasse definições sobre ela, a mídia se torna um dos principais atores na resposta inicial para a Aids no Brasil. E com a mídia, as primeiras classificações da Aids que, como acontecia em outros países, como Estados Unidos, aparece vinculada a um grupo com um comportamento sexual especifico: os homossexuais. Este momento corresponde ao primeiro quadro de significados sobre a doença, cuja representação é a sua vinculação com a homossexualidade e a identificação como "câncer gay". Uma das primeiras matérias sobre a Aids foi noticiada em 1981, no Jornal do Brasil, e trazia como título: "Câncer em homossexuais é pesquisado nos EUA" . Nessa linha, a mídia se torna um dos principais atores a instituir maneiras de ver e julgar a constituição da Aids como um problema público.

7. Vários outros exemplos podem ser dados dos anos seguintes: "Doença misteriosa leva à morte os homossexuais”, publicada no jornal 0 Globo de 1981; “Doença nova atinge homossexuais nos EUA”, publicada, como tradução literal da matéria do New York Times, no Jornal do Brasil, em 1982; "Mal Particular”, na revista Veja, de 14/07/1982; "Tragédia venérea: o mal dos homossexuais americanos”, título da 
0 aparecimento dos primeiros casos em brasileiros que haviam viajado para o exterior e a intensa circulação na mídia coloca em destaque os homossexuais, os quais passam a representar o grupo mais diretamente afetado pela primeira fase de construção pública da doença. Tal conjuntura gera um efeito na mobilização por parte do movimento homossexual que se vê na condição de reagir frente à situação. Dessa forma, a atuação da mídia na publicização do problema e na definição da Aids constitui-se como um evento chave, uma vez que chama para o debate ativistas do movimento homossexual, contribuindo para organizar as experiências destes protagonistas.

Como define Galvão (2000), além dos grupos gays no estado de São Paulo, tiveram forte influência na forma como a doença seria tratada, o Grupo Gay da Bahia e o Dialogay de Sergipe. Estes grupos são apontados, pela bibliografia específica sobre a Aids, como aqueles que conseguiram conjugar a luta contra o preconceito, e em busca da legitimidade dos homossexuais, com a construção de uma resposta à epidemia (GALVÃO, 2000; FACCHINI, 2005).

Campanhas de valorização da homossexualidade, atividades, ofıcinas, palestras, distribuição de preservativos e apostilas com informações sobre a doença, direcionadas ao público homossexual, assim como denúncias de violência, foram as principais iniciativas do movimento homossexual em resposta à Aids. Podemos tomar este como o momento em que ele deixa de ser um problema midiático e passa a exigir atuação de grupos organizados em torno de uma resposta para a doença. Nesta fase, é inicial- mente dentro do movimento homossexual que a doença passa a ser tratada e com isso os comportamentos sexuais passam a ocupar um lugar no debate sobre a epidemia.

Ao mesmo tempo em que a Aids foi devastadora para os homossexuais, ampliando o preconceito e o estigma, e levando à morte, ela também permitiu colocar em evidência a existência de uma comunidade gay real, com um comportamento sexual específico e com uma vida cultural e social ativa. Assim, a epidemia coloca em evidência na sociedade um grupo cujas práticas eram vividas, na maior parte das vezes, de modo clandestino e em segredo (POLLACK, 1990). Os quadros de significados que aparecem, neste momento, associam a luta contra a Aids à luta contra o preconceito e mostram a necessidade de desvincular a doença dos chamados "grupos de risco", dos quais os homossexuais eram parte central. 0 relato abaixo, de um dos principais ativistas do movimento homossexual nos anos 1980, ilustra o efeito da doença no ativismo gay e na visibilidade do movimento.

0 impacto da AIDS foi devastador. Mas também surpreendentemente positivo. Seus elementos negativos são evidentes: reforçou a homofobia em alto grau e diminuiu em muito a autoestima de pessoas homossexuais. Não foram poucos os homossexuais que se mataram, no auge da epidemia. Sem falar daqueles que entraram em parafuso e decidiram "converter-se” em heterossexuais, a partir dos conflitos que passaram a viver. Mas costumase esquecer que a AIDS teve um efeito colateral tremendamente positivo. Bem ou mal, ela levou para as primeiras páginas dos jornais

revista Isto É de 1983; “Doença dos homossexuais atinge o país”, no jornal Folha de São Paulo, de 1983. Uma análise mais detalhada sobre a produção de notícias sobre a AIDS pode ser encontrada em Galvão (1992) e Nascimento (2000). 
a existência de homossexuais concretos (como atores de Hollywood e da Globo, que faleceram em decorrência da enfermidade) e, sobretudo, a vivacidade de uma cultura e vida homossexuais. A sociedade foi bombardeada, a contragosto, com informações de que gays existiam, tinham nome e endereço - podiam ter o rosto de Rock Hudson, por exemplo, ou de Lauro Corona e Cazuza. Em resumo, homossexuais tornaram-se mais visíveis. Quando um médico denunciava que existiam saunas gays promíscuas, estava brandindo uma faca de dois gumes: através dele a população era informada de que homossexuais tinham um estilo de vida próprio, ainda que imposto marginalmente pela sociedade, e eram muito ativos no exercício da sua sexualidade. Não me parece exagerado dizer que, apesar e em meio à tragédia, a AIDS consolidou socialmente a idéia da existência concreta de uma comunidade homossexual. Nesse sentido, acho que dois anos de AIDS podiam equivaler a 10 anos de esforços de visibilidade do movimento pelos direitos homossexuais ${ }^{8}$.

Podemos perceber que a emergência da Aids como um problema público coloca em evidência um conjunto de moralidades coletivas. 0 registro dos primeiros casos da doença no mundo e no Brasil, e sua vinculação com a homossexualidade, desempenharam um impacto decisivo na reestruturação do movimento homossexual. Nesse sentido, a história da luta contra a Aids está associada à luta em defesa dos direi- tos homossexuais, uma vez que ela trouxe à tona uma discussão sobre liberdades, sexualidade e comportamento sexual. A epidemia, como aponta Pollack (1990), permitiu reagrupar e dar uma unidade ao movimento que até então se encontrava disperso e fragmentado. No Brasil, a atuação do movimento homossexual na resposta à epidemia foi tão forte, que já no início dos anos 1980 tornava-se difícil distinguir a militância do movimento homossexual e o engajamento na luta contra a Aids. A pauta do movimento foi afetada profundamente pelo combate à Aids e voltada à luta por políticas de saúde que prestassem serviços de assistência ao doente, e que permitissem um tratamento adequado aos portadores do vírus. Se antes o movimento focava em campanhas de conscientização e defesa dos direitos dos homossexuais, agora suas pautas são atravessadas pela Aids.

$\mathrm{Na}$ mesma direção em que os líderes do movimento homossexual estavam se mobilizando em torno da doença, pressionando governos e investindo em campanhas de prevenção e auxílio psicológico, outro grupo de atores passava a encarar a doença e a se manifestar diante da epidemia. São os médicos sanitaristas ${ }^{9}$ os primeiros profissionais da saúde a se envolverem no debate político e nacional acerca da doença. Suas intervenções partem principalmente de dentro de instituições científıcas, setores públicos de tratamento de epidemias e doenças infectocontagiosas (como a hanseníase) e das uni-

8. Entrevista com João Silvério Trevisan, cineasta e militante do Movimento LGBT. Disponível em <http://www. crprj.org.br/publicacoes/jornal/jornal19-joaosilveriotrevisan.pdf> Acesso em MARÇ0 DE 2014. 9. 0 médico sanitarista como especialidade médica ocorre, em 1927, com a criação do primeiro Curso de Higiene da Saúde Pública, destinado a formação do médico sanitarista e ministrado pela Faculdade de Medicina do Rio de Janeiro, numa parceria com o Instituto Oswaldo Cruz. A criação desta especialidade representou uma abertura dentro do Estado e uma inserção dos médicos como formuladores de políticas de saúde (AVILA, 1988). 
versidades. Este setor da medicina, por historicamente estar mais envolvido com epidemias e com a saúde pública, se mobiliza diante da doença. Contudo, os médicos sanitaristas são chamados ao debate em função das primeiras propostas governamentais de resposta à epidemia - o recurso à expertise médica sanitária se torna um dos principais motes da luta contra a epidemia no cenário brasileiro. Nessa fase de mobilização e formação de grupos, os espaços de onde são recrutados os militantes derivam, num primeiro momento, do movimento homossexual e, num segundo momento, do movimento sanitarista e da medicina sanitária.

\subsection{A inserção da AIDS na agenda política: sanitaristas e ativistas}

A segunda fase de construção do problema é o momento em que ele passa a constar na agenda política e o momento em que se tomam medidas governamentais para tratar o problema. A intensa pressão política feita pelo movimento homossexual no país impulsiona as primeiras iniciativas governamentais para enfrentar a doença. Ao contrário do que aconteceu em outros países, como os Estados Unidos, por exemplo, a atuação do movimento se volta para o Estado, na tentativa de criar serviços de ajuda aos doentes e ações voltadas à cidadania dos pacientes. Essa característica que toma a luta contra a Aids no contexto brasileiro é favorecida, em certa medida, pelo processo de redemocratização e retomada da abertura política que coloca em evidência governos interessados em explicitar o processo político e inserir a sociedade civil no debate. Além disso, as próprias lideranças do movimento homossexual estavam inseridas em espaços de contestação e em frentes de resistência contra a ditadura que lhes permitiram, por um lado, estabelecer laços e criar vínculos com militantes voltados à luta contra a censura - e com a democracia passaram a ocupar cargos políticos; por outro lado, estas lideranças puderam partilhar de uma visão de cidadania que envolvia a atuação e a proteção do Estado. Todas essas questões criaram espaços de sociabilidade e se tornaram oportunidades e contingências para politizar o debate da Aids.

0 percurso de uma das lideranças do movimento homossexual pode ilustrar essa múltipla inserção. Considerado um dos principais ativistas na luta contra a discriminação sexual, João Silvério Trevisan foi um dos fundadores de uma das principais mídias alternativas durante o regime militar. Tratava-se do jornal Lampião de Esquina, fundado em 1978 por um grupo de jornalistas e escritores homossexuais, que trazia forte debate não só sobre os direitos homossexuais, mas também sobre o direito das minorias em geral, como negros e mulheres, e atuava na defesa da cidadania e liberdade democrática - com participação destacada na campanha pela anistia. Tal jornal voltava-se tanto para formação de uma consciência política quanto sobre sexualidade. João Silvério esteve presente em diversos eventos de contestação ao regime, sobretudo aqueles organizados pela esquerda universitária. Junto com outros militantes de esquerda fundou também o grupo So$\operatorname{mos}^{10}$, em São Paulo, o qual teve um papel importante na mobilização contra a Aids.

10. Grupo de afirmação homossexual que atuou em defesa dos direitos homossexuais, fundado em 1978. 0 Somos teve um papel importante na formação de um movimento homossexual e no estímulo à criação de diversos grupos em todo o país. 
A criação do primeiro programa público de combate à epidemia organizado pelo estado de São Paulo demonstra a articulação entre as lideranças do movimento homossexual e as políticas de Aids. Este programa foi criado em 1983 e inaugura a parceira entre lideranças do movimento homossexual, médicos ativistas na Reforma Sanitária ${ }^{11} \mathrm{e}$ na militância política. A iniciativa foi dada pelo então secretário de saúde do primeiro governo democrático pós-ditadura militar ${ }^{12}$, João Yunes, que solicitado pelo movimento homossexual paulista, sobretudo pelo grupo Somos, criou a primeira equipe técnica para discutir a questão. João Yunes era um médico paulista sanitarista, ativista no movimento de reforma sanitária, que havia participado dos movimentos contestatórios contra o regime militar nos anos 1960 e 1970, destacando-se na criação do grupo Ação Popular ${ }^{13}$. Antes de assumir essa função já havia ocupado cargos no Ministério da Saúde e no governo estadual. Junto com Sergio Arouca ${ }^{14}$, se constituiu como um dos principais representantes do Movimento de Reforma Sanitária dos anos 1980.

À frente da equipe, foi designado o seu primeiro coordenador, o médico especialista em dermatologia sanitária, chefe do Departamento Estadual de Hanseníase e Dermatologia Sanitária, Paulo Roberto Teixeira. Assim como Yunes, Paulo Teixeira havia participado intensamente da militância estudantil de esquerda no período do regime militar, integrando o grupo Ação Popular em São Paulo. Além da inserção na fundação de um dos principais grupos gays de São Paulo - o Somos - participou de grupos e movimentos que foram influenciados pelo movimento sanitarista. Neste programa, Paulo Teixeira constituiu uma equipe de médicos e lideranças do movimento homossexual, dentre eles o presidente do grupo Somos. 0 movimento homossexual teve um papel determinante no contato com a comunidade gay, por meio de atividades, palestras e oficinas. 0 relato abaixo feito por Paulo Roberto Teixeira, em uma entre-

11. 0 movimento sanitarista no Brasil tem diferentes fases. Uma delas foi denominada de Reforma Sanitária e emerge no final dos anos 1970 com o objetivo de rever as políticas de saúde, propor uma democratização no acesso à saúde e tomando a mesma como responsabilidade do Estado. A proposta que estava na base desta reforma vinculava a necessidade de uma medicina social, comunitária e preventiva. Seus idealizadores foram médicos profundamente marcados pela luta contra a ditadura e pelo marxismo, e que articulavam classes sociais e saúde. A bandeira era a conscientização da população como instrumento de saúde pública. 0 movimento é liderado por médicos que atuavam no Departamento de Medicina Preventiva e Social da UNICAMP, mas com as pressões dos militares e as respectivas demissões, muitos foram atuar na FIOCRUZ e no Instituto de Medicina Social da Universidade do Estado do Rio de Janeiro. Além disso, este movimento teve um papel central na redemocratização da saúde nos anos 1980, esteve à frente da criação do SUS (Sistema Único de Saúde) e na composição de programas de saúde pública, como os denominados DSTs/Aids.

12. Trata-se do governo Franco Montoro, eleito em 1982, na primeira eleição direta após a ditadura.

13. João Yunes foi um dos ativistas do grupo Ação Popular. Ação Popular foi um partido clandestino fundado por antigos militantes da Juventude Universitária Católica (JUC) que buscavam aprofundar a inserção na esquerda sem a interferência católica.

14. Foi um dos principais expoentes do Movimento de Reforma Sanitária nos anos 1970 e um dos mais destacados articuladores e formuladores do Sistema Único de Saúde. Sua tese de doutorado intitulada: "0 dilema preventivista: contribuição para a compreensão e crítica da medicina preventiva” forneceu as bases teóricas para a reestruturação da saúde pública nos anos 1980. 
vista concedida à jornalista Martha França (2008), ilustra como ocorreu a situação que desencadeou numa das primeiras propostas de institucionalização da Aids.

Um grupo de militantes pelos direitos dos homossexuais procurou o Yunes para cobrar uma posição sobre o problema, que começava a ter repercussão no âmbito da imprensa. Eu era muito amigo do João Silvério Trevisan, um dos participantes desse grupo. Em 1976, ele tinha acabado de chegar de Berkeley, nos Estados Unidos, e nós organizamos na minha casa algumas reuniões informais para discutir questões relacionadas com a organização de um grupo pelos direitos dos homossexuais. Depois disso, eu fui para a França fazer um estágio, que acabei não fazendo por razões pessoais, e voltei no começo de 1977, quando comecei a me preparar para o exame de especialidade em Dermatologia. Nesse intervalo, o Trevisan e o Celso Cury, outro participante do movimento, tinham voltado a se reunir e eu me incorporei ao grupo. Fundamos o grupo Somos, do qual participei até 1979 , quando saí por questões mais internas e também porque a militância na área de saúde me puxava muito (...). Mas, de 1979 a 1983 eu não voltei a ter contato com o grupo, embora continuasse sendo amigo de todos. A comissão que foi organizada era composta de médicos sanitaristas, infectologistas, especialistas da área de laboratório e social. Ela concluiu que, embora fossem poucos casos confirmados no Brasil, era um agravo inusitado à saúde que estava provocando pânico na população e deveria ser investigado pelo Estado (FRANÇA, 2008, p. 4)

Após constituir o programa, Paulo Teixeira contou com a colaboração de entidades do movimento homossexual que participavam oficialmente - como é o caso do grupo Outra Coisa - e havia também aqueles que davam uma contribuição sem comprometimento formal. Este último é o caso de João Trevisan e Jean Claude Bernard, respectivamente do grupo Somos e do jornal Lampião de Esquina, que não aceitaram compor ofıcialmente a comissão que organizaria o programa, mas participaram do processo frequentando as reuniões, dando suporte e sugerindo estratégias. As principais formas de ação do programa foram: reuniões públicas com a comunidade para esclarecimentos sobre a doença, folhetins informativos sobre formas de contágio, e distribuição de boletins e textos visando diminuir o preconceito e a discriminação. É de dentro deste programa que surge a primeira organização voltada à causa da Aids, como veremos no tópico posterior: o GAPA.

Como se pode observar, a articulação entre um movimento homossexual ativo, um espaço de investimento intenso na medicina sanitária e um governo interessado em inserir os movimentos sociais no debate político criaram as condições favoráveis para o aparecimento da primeira resposta governamental para a doença. Além disso, estes movimentos tinham uma forte ligação entre si, uma vez que estavam vinculados à luta contra a ditadura e pertenciam a rede de relações que os aproximavam. É dessa forma que os saberes mobilizados na luta contra a Aids se manifestam, da articulação entre um saber militante, obtido por meio da participação no movimento homossexual, e um saber médico. Cabe salientar que este saber médico é indissociável de um saber militante, pois resulta também da participação em redes e espaços de mobilização política, como a luta contra a ditadura, e do investimento nos movimentos de reforma sanitária, a partir dos quais foi possível para os envolvidos uma concepção determinada de saúde pública. 
As respostas iniciais à Aids são dadas pela articulação entre movimento homossexual e médicos sanitaristas. Os médicos sanitaristas tiveram um papel central na mediação entre saberes políticos e científicos, mobilizando o conhecimento e experiência que tinham em torno de doenças transmissiveis e infecciosas, a um saber político manifestado pela participação em espaços de mobilização e luta por determinada concepção de saúde. Essas condições foram determinantes para que a Aids fosse tratada como um problema de saúde pública e que exigia a imediata intervenção do Estado. Tratava-se de médicos engajados na luta pela saúde pública.

Esta fase da construção da Aids, como um problema social, é marcada pela intensa mobilização voltada a políticas de Aids e ação governamental, de onde emerge um conjunto de atores e discursos. Destaca-se, nesse caso, também a implementação de uma política nacional da Aids, a qual se torna um evento importante na formação de novas redes, uma vez que sua consolidação é acompanhada de acordos internacionais e de uma reformulação no sistema público de saúde. Em 1986 é criado um programa nacional para a Síndrome da Imunodeficiência Adquirida e, em 1988, uma reforma no sistema de saúde com a criação do Sistema Único de Saúde (SUS). Este período é marcado por uma intensa participação dos médicos, voltados especificamente à medicina sanitária, como formuladores de políticas, articuladores e coordenadores do programa nacional. Dos seis coordenadores do Programa Nacional e da Campanha da Aids, quatro são médicos sanitaristas, vinculados à dermatologia e à pediatria sanitária. 0 programa emerge, no início, sob a coordenação da Divisão Nacional de Dermatologia Sanitária, que historicamente esteve à frente de doenças contagiosas que exigiam isolamento social, como a hanseníase. É somente em 1988 que o programa passa a ter uma vinculação direta com o Ministério da Saúde.

A articulação do programa com departamentos sanitários explica, em parte, as atuações dos médicos sanitaristas na condução das políticas. Por um lado, o investimento dos médicos sanitaristas dependeu da forma como a doença foi tratada pelo Estado, que departamentos se responsabilizaram por ela, e a própria concepção inicial de que ela representava um problema de saúde pública, como foram outras doenças no passado, a exemplo da hanseníase. Por outro lado, a medicina sanitária representou um setor importante de especialidade com forte caráter político e de intervenção pública. Assim, como especialidade médica, ela já apresentava forte inserção no espaço político.

No início dos anos 1990 começam os primeiros acordos internacionais nas políticas brasileiras de combate à Aids, como o acordo assinado com o Banco Mundial e outras entidades internacionais, como a UNICEF, OMS, Coordenação das Nações Unidades no Combate às Drogas. 0 financiamento com o Banco Mundial foi decisivo para um redirecionamento da política, uma vez que ele permitiu que as ONGs fossem beneficiadas por meio de editais e projetos que prestassem algum tipo de serviço à comunidade. Este período, que tem início no final dos anos 1980, representa um envolvimento de diferentes níveis dos programas governamentais com os movimentos sociais e as organizações não governamentais, caracterizando-se pela intensa articulação entre eles na construção da luta contra a Aids.

Além disso, esse momento representa uma intensa articulação internacional dos programas nacionais. Tal fato é tão impor- 
tante que tem impacto decisivo nas carreiras dos próprios coordenadores. Dos seis coordenadores mapeados nesta pesquisa, três deles apresentam inserção destacada em instituições internacionais, como o Programa de Aids da ONU (UNAIDS), OMS e OPAN. Este é caso principalmente do médico dermatologista sanitário Pedro Chequer, que deixa o cargo de coordenador do programa nacional para atuar como coordenador da UNAIDS no Brasil. Pedro atuou na coordenação do programa nacional por duas gestões. $\mathrm{Na}$ primeira, de 1996 a 2000, ele deixa o cargo para assumir o posto da UNAIDS no Cone Sul. Na segunda, de 2004 a 2006, ele deixa o cargo para assumir como coordenador da instituição em Moçambique, e desde 2008 representa a instituição no Brasil. Outros dois nomes podem ser apresentados ainda: o médico dermatologista sanitário Paulo Roberto Teixeira, que deixa o cargo em 2003 para assumir a coordenação do programa de AIDS da OMS, e a médica sanitarista pediatra Mariângela Simão que também sai da coordenação nacional, em 2010, para assumir a coordenação de prevenção na UNAIDS. Esta intensa circulação dos gestores de políticas nacionais em espaços internacionais depende, de um lado, da própria configuração da política de Aids no país e seu contato com agências internacionais (ela cria um espaço de sociabilidade entre os agentes, permitindo aos que dela participam uma série de contatos, laços sociais e experiências, que se dão pela participação na política, e que permitem um acesso às redes internacionais). De outro lado, o reconhecimento internacional do programa brasileiro ${ }^{15}$ estimula aos seus gestores oferecer suas experiências nas políticas de Aids aos órgãos internacionais e serem por eles cooptados. Assim, o programa se constitui como um canal de acesso às redes internacionais.

A intensa articulação entre as políticas públicas de combate à doença e os movimentos sociais coloca o Brasil como um dos países que possuem as políticas nacionais mais avançadas no combate à Aids, uma vez que tal articulação se apresenta numa proposta até então tida como inédita no tratamento da doença. Considerado como uma marca brasileira, este modelo está organizado pelo financiamento direto do governo às organizações não governamentais.

0 intenso investimento do Estado nas associações e organizações não governamentais promoveu uma mudança no perfil das lideranças e das próprias entidades que precisaram se adequar às exigências para concorrer aos editais e obter os financiamentos para seus projetos. Dentre estas exigências está a capacidade técnica da instituição de contar com profissionais qualificados que possam assumir os projetos. Isso inclui médicos, assistentes sociais, psicólogos, dentre outros. Tal fato levou ao desaparecimento de muitas entidades que não conseguiram se adequar aos critérios e, ao mesmo tempo, permitiu o surgimento de outras.

É importante destacar que as respostas à doença emergem no Brasil no contexto da redemocratização. Neste contexto, pode-se observar uma diversidade de movimentos sociais, desde aqueles que viviam na clandestinidade até aqueles que encontram um espaço de sobrevivência política.

15. O Programa recebeu, ao longo dos anos, algumas premiações importantes, dentre elas a da OMS e da ONU, em 2001, como um programa de referência internacional. 
A reabertura tornou necessária a demonstração do processo democrático por meio da participação massiva das organizações e movimentos sociais nas políticas sociais, como uma maneira de destacar a interlocução com grupos anteriormente banidos da política (LANDAU, 2011). Os movimentos de maneira geral, e podemos incluir aqui aqueles constituídos por categorias profissionais como, por exemplo, o Movimento de Reforma Sanitária, atuaram de forma significativa, inclusive no desenho da constituição de 1988, chamada de constituição cidadã.

Ao mesmo tempo, é neste contexto que ocorre ainda a reestruturação do serviço público de saúde, que passa a ser denominado SUS (Sistema Único de Saúde) e que tem como principal referência a saúde como direito de todos e responsabilidade do Estado. Estiveram à frente da sua formulação lideranças médicas do movimento de Reforma Sanitária, que traziam como bandeira a medicina preventiva e comunitária. Antes da criação do SUS, a saúde não era considerada um direito de todos, apenas dos que contribuíam para o Instituto de Previdência Social- denominado INAMPS. Além do SUS se constituir como uma proposta de saúde para todos, com ele emerge também uma descentralização dos recursos para saúde. Assim, estados e municípios poderiam aplicar as verbas para serviços de saúde pública. Somaram-se a estes fatores a distribuição gratuita do coquetel de medicamentos retrovirais, conhecido como HAART (Highly Active Antiretroviral Therapy), sem custo algum para população infectada, conforme Lei Sarney de 1996. Ainda é possível observar que desde 2007, por meio de uma medida governamental, o SUS distribui drogas genéricas para compor o Haart, produzidas no Brasil.

\subsection{A emergência do "Ativismo de AIDS": soropositividade, engajamento político e atuação profissional}

A terceira fase de constituição da Aids como um problema público é a emergência do ativismo de Aids através do aparecimento de um conjunto de associações e organizações. Essas associações que passam a compor a arena pública têm como principal característica a soropositividade e a experiência da doença. Tal peculiaridade tem sido vista como um dos ingredientes do engajamento na luta contra a doença. Contudo, a Aids não foi a primeira doença a mobilizar engajamentos a partir dos doentes, outras enfermidades do passado já demonstraram ser a experiência da doença um elemento constitutivo da mobilização - como por exemplo, a associação de pessoas com diabetes, com câncer, dentre outras. 0 diferencial da Aids com relação a outras doenças, segundo Bastos (2002) está na capacidade de intervenção e politização do atingidos pela Aids. Assim, tal característica deste ativismo nos permitiu indagar quem são e a que espaços estão conectadas as principais lideranças do "ativismo de Aids" no Brasil. Isso nos encaminhou à terceira fase de defınição da Aids como problema coletivo.

Por um lado, a fragmentação sofrida pelo movimento homossexual e sua dispersão em outros grupos, como mulheres e negros homossexuais que não se sentiam representados pelas organizações homossexuais, contribuiu para dividir muitas entidades que acabaram por ser extintas. Além disso, a maioria dos grupos já se encontrava dividida entre aqueles que associavam a luta homossexual a uma "luta maior”, como a democracia, e aqueles que acreditavam na defesa de uma causa homossexual independente do debate políti- 
co. Um exemplo disso é a própria história do grupo Somos que já no início dos anos 1980 enfrentou a saída das mulheres e das lideranças que apoiavam o alinhamento partidário do movimento. Isso contribuiu para dar origem a dois grupos distintos: Ação Lésbico-Feminista e o Outra Coisa. A dispersão entre os grupos se tornou tão intensa que dos 22 grupos atuantes no país em 1980, restaram quatro em 1985 e três em 1986 (FIGARI, 2007).

Por outro lado, a política nacional de Aids criava as condições para que grupos específicos voltados à causa da Aids compusessem os projetos na luta contra a doença. 0 enfraquecimento das organizações voltadas à causa homossexual e o aparecimento de grupos que se fortaleceram a partir do vínculo com os projetos estatais, nacionais e políticas de Aids, marcam esse momento do ativismo. Acordos entre o governo federal e órgãos internacionais para fins de financiamento, estimularam a criação de ONGs/Aids em todo o país. 0 período que se estende de 1992 até 1997 é apresentado como um momento de intenso envolvimento dos programas estaduais e federais com as organizações não governamentais, o que estimulou a criação de muitas delas. Em 1992 existiam 82 ONGs/Aids e em 1994 mais de 250 são constituídas no país (FIGARI, 2007).

Assim, para participar do processo de ação e decisão pública do Estado e para ser identificada na arena pública - compondo comissões, participando de redes de negociações, recebendo financiamento - os atores coletivos são levados a se organizar em associações. Adquirir essa condição jurídica é essencial para a sobrevivência política das organizações e para sua capacidade de participação nos processos de decisão política. É em função disso que podemos observar um aumento expressivo de novas organizações e associação na luta por direitos, de modo geral.

A terceira fase de construção do problema é caracterizada, portanto, pelo aparecimento das chamadas $0 \mathrm{NG} /$ Aids. Estas diferentes fases da construção ocorrem em um contexto de transformação da política nacional, a qual vivia a passagem de um modelo político ditatorial para uma democracia. 0 retorno de antigos militantes de esquerda do exílio, a expansão e consolidação dos movimentos sociais e a reestruturação dos partidos políticos tiveram uma forte influência para a forma como a causa da Aids seria tratada no cenário brasileiro e os saberes possiveis de serem mobilizados na sua defesa.

Assim, em meados dos anos 1985, começam a aparecer as primeiras organizações voltadas especificamente para tratar o tema da Aids, como é o caso do surgimento do GAPA (Grupo de Apoio a Pessoas com Aids) em São Paulo, como a primeira ONG/ Aids brasileira; a Associação Brasileira Interdisciplinar da Aids (ABIA), criada em 1986 no Rio de Janeiro e, em 1989, o Grupo Vidda também no Rio de Janeiro. Estas são tidas como as primeiras entidades no país a dedicar uma atenção exclusiva ao tema da Aids, direcionadas, seja para prestar auxílio aos portadores do vírus, como para pressionar o Estado a assumir uma postura mais destacada diante da epidemia. Tais entidades apresentam algumas características comuns: a criação e articulação por especialistas e membros de profissões específicas que se viram contaminados pelo vírus, e que tinham, ao mesmo tempo, uma contribuição técnica a ser oferecida à causa. Esta situação conduziu a uma reformulação dos serviços prestados que, além de servirem de assistência médica às vitimas, também ser- 
viriam de auto-suporte. Da primeira ONG/ Aids de 1985 até 2010 foram registrados, pelo Ministério da Saúde, 695 entidades voltadas especificamente a este tema.

Estas organizações tiveram um papel central na política de Aids, destacando-se na prestação de serviços, na pressão para políticas de saúde pública, na organização de eventos, congressos e nas conexões com entidades internacionais. No início da epidemia no país havia poucos doentes, mas no final dos anos 1980 a situação era dramática, uma vez que não havia leito para todos os doentes, nem formas de tratamento suficientemente eficazes para dar uma qualidade de vida. Além de não haver condições públicas para o recebimento destes pacientes, tais como leito disponível, verbas públicas para tratamento e prevenção, não se sabia o que fazer, sabia-se apenas que era preciso prestar algum tipo de socorro, mas era certo o prognóstico da morte. Tal situação é com frequência definida pelos ativistas como os "anos heroicos" da luta contra a Aids (GALVÃO, 2000).

Nesse sentido, o aparecimento das primeiras organizações que se voltam especificamente para a questão da Aids é marcado por um ativismo caracterizado pela intensa articulação entre militância política e profissionalização dos serviços. A emergência de setores profissionais e a entrada de membros de profissões específicas no debate, oferecem novos significados na constituição da Aids como um problema público. Dentro deste quadro, as ONGs/ Aids, como são denominadas, se caracterizam por quadros de profissionais que, em nome de um conhecimento específico, se posicionam na luta contra a doença. Podemos citar o caso do GAPA São Paulo fundado em 1985 por militantes de esquerda, membros do movimento homossexual, exmilitantes do grupo Somos, advogados e médicos que haviam atuado no Programa Estadual de Atenção à Aids de São Paulo. A união entre os membros das equipes técnicas do programa e lideranças do movimento homossexual deu origem à criação do GAPA. Com o lema atual "Você não está Sozinho nesta Jornada", o grupo tem como missão a defesa dos direitos humanos e a integração das pessoas infectadas pelo vírus na sociedade.

Além do GAPA, a Associação Brasileira Interdisciplinar da Aids (ABIA), fundada pelo sociólogo Herbert de Souza - Betinho ${ }^{16}$ como ficou conhecido - representa com sucesso a articulação entre saberes profissionais e militância política. Altamente organizada por um quadro de especialistas e militantes, sobretudo aqueles engajados na luta contra o regime militar e movimento homossexual, contou, desde a sua fundação, com profissionais de diversos setores, com presença na vida política e, de início, obteve múltiplos financiamentos. Betinho, assim como muitos dos principais fundado-

16. Betinho se destacou no cenário nacional em função da Campanha pela Anistia. Importante militante político no período da ditadura militar, tem uma história marcada pela intensa atuação política, a qual tem início na juventude católica durante o ensino médio. Mais tarde, no período da sua graduação em Sociologia na Universidade de Minas Gerais, intensifica sua atuação na Juventude Universitária Católica (JUC) e, em seguida, na fundação do grupo Ação Popular. Este último representava uma dissidência da JUC e visava uma atuação mais aprofundada na esquerda sem a interferência católica. Antes da ditadura militar, já havia ocupado alguns postos no Estado, como assessor do Ministro da Educação do governo de João Goulart. Exilado no período dos governos militares, na década de 1960, fortalece seus investimentos fundando, junto com outros exilados, instituições de pesquisa sobre a América Latina. 
res das primeiras organizações, era também portador do vírus da Aids. Seu engajamento político é muito anterior ao contágio e já se destacava na luta contra o regime autoritário, tornando-se um dos exilados da ditadura militar. Antes de descobrir-se portador do vírus e aderir à causa da AIDS, dedicouse a várias causas sociais e fundou também outras instituições, com destaque para o Instituto Brasileiro de Análise Social e Econômica (IBASE) ${ }^{17}$. Essas experiências anteriores lhe possibilitaram inserção em redes de relações diversificadas, as quais foram fundamentais para a fundação da ABIA.

A ABIA surge das iniciativas do Betinho junto ao IBASE e mobilizou um conjunto de intelectuais de esquerda, médicos ativistas no movimento de reforma sanitária e pesquisadores da Fundação Oswaldo Cruz - instituição com um histórico na medicina sanitária. De início a instituição, que passa a ser coordenada por ele e pelo médico Walter Almeida, consegue importantes financiamentos. Um deles foi o do Instituto Nacional de Medicina e Previdência Social (INAMPS), por meio do então diretor Hésio Cordeiro $^{18}$, amigo de Betinho e médico sanitarista, ativista em prol de uma medicina social e preventiva. Cordeiro foi um dos representantes do Movimento de Reforma Sanitária nos anos 1970 e membro do Centro
Brasileiro de Estudos da Saúde ${ }^{19}$ (CEBES), o qual fornecia informações sobre a conjuntura da saúde para o IBASE, prestando uma espécie de assessoria (SOPHIA, 2012). A relação entre o CEBES e o IBASE também se intensificou por meio da organização de eventos e seminários. Destacaram-se ainda os financiamentos obtidos pela Financiadora de Estudos e Projetos (FINEP) e pela Fundação Ford. 0 primeiro foi obtido por meio das relações entre a cientista política Silvia Ramos - membro do IBASE - e o presidente da FINEP, na ocasião Reinaldo Guimarães - que era médico sanitarista. 0 segundo, por meio do antropólogo Peter Fry, que também participava das reuniões no IBASE, e que no momento era representante da Fundação Ford no Brasil. Este impulso inicial conquistado via intensa rede de relações que giravam, ora em torno do Betinho, ora em torno do IBASE, permitiu a contratação de profissionais para atuar em tempo integral na associação. Tais redes eram oriundas fundamentalmente de dois espaços: luta pela reforma sanitária e espaços de contestação política.

Nas décadas seguintes, a associação conquistou respaldo internacional diante das agências de financiamento, como Organização Mundial de Saúde (OMS), Organização Pan Americana de Saúde (OPAS), e múlti-

17. O IBASE foi fundado em 1981 por Betinho e dois companheiros da militância política no exílio, o economista Marcos Arruda e Carlos Alberto Afonso. Betinho e Carlos Alberto já haviam fundado, durante o exílio político no Canadá, uma instituição de pesquisa e estudos sobre a América Latina, a LARU (Latin-american Research Unity). Com a lei da anistia, em 1979, retornam ao país com o projeto de uma instituição que deveria funcionar como pesquisa e também como monitoramento das políticas públicas.

18. Junto com Sérgio Arouca, foi um dos principais ativistas do Movimento de Reforma Sanitária da década de 1970 que culminou na idealização e construção do Sistema Único de Saúde, em 1988.

19. 0 CEBES foi fundado em 1976, em São Paulo, e constituiu-se num dos principais espaços de encontro e discussão sobre saúde entre médicos e sanitaristas. 0 Centro teve uma forte articulação com as ciências sociais e humanas e representou um importante espaço de formulação e proposição de políticas de saúde. Agregou, desde a sua fundação, médicos e cientistas sociais provenientes, sobretudo, da esquerda universitária da USP (SOPHIA, 2012). 
plos acordos internacionais. Por influência de Walter Almeida, um dos diretores, a ABIA participou da fundação da Rede Latino Americana de ONGs/Aids, nos anos 1990, além de articular a criação do Conselho Internacional de Organizações para Serviço da Aids. Sua atuação voltou-se a para a pressão junto aos órgãos governamentais em torno de políticas de Aids e sobre o sistema brasileiro de sangue. Betinho, que se contaminou com o vírus da Aids devido às constantes transfusões de sangue a que era submetido por ser hemofílico, lutou por meio da ABIA contra a comercialização de sangue no Brasil, vencendo uma dura batalha.

Formada, desde o seu nascimento, por intelectuais, ativistas, médicos, antropólogos, sociólogos, a associação destacou-se na pesquisa social e no ativismo político na luta contra a Aids. 0 foco central das pesquisas dirigidas pela instituição estava voltado às ciências sociais e humanas, com temas como impacto social da Aids, história social da Aids, Aids e as mulheres, cujo objetivo era instrumentalizar o governo, e também as outras organizações não governamentais, para estabelecimento de políticas públicas e estratégias efetivas de combate à doença. Nessa linha, a instituição se caracterizou por uma atuação multidisciplinar que agregasse a produção de conhecimento sobre a doença e a ação e intervenção social.
0 Grupo pela Vidda tem características semelhantes, uma vez que surge como um projeto da ABIA. Foi fundado por Herbert Daniel, sociólogo, militante de esquerda, um dos exilados da ditadura militar, militante do Partido dos Trabalhadores (PT), fundador do Partido Verde (PV), além de ativista pelos direitos dos homossexuais. Daniel ${ }^{20}$, que também era portador do vírus, já havia participado ativamente da fundação da ABIA, da qual foi presidente. É de dentro da ABIA que surge a necessidade de criar uma organização que prestasse algum tipo de auxílio aos portadores do vírus e que lutasse pelos direitos das pessoas que vivem com Aids, servindo assim como porta voz político. Procurando minimizar os efeitos que a noção de "sentença de morte" desempenhou no curso da doença, o grupo teve como principal questão: como viver com Aids? Para isso a instituição conta com um aparato profissional que envolve atendimento psicossocial, com assistentes sociais e psicólogos e atendimento jurídico, com advogados. Estes últimos atuam no aconselhamento na área trabalhista e previdenciária.

Também podemos citar o Grupo de Incentivo à Vida (GIV), criado em 1990, por um psicólogo ${ }^{21}$, também portador do vírus. 0 GIV é considerado o primeiro grupo de ajuda mútua da América Latina, formado e dirigido por portadores do vírus. Os principais atores a se destacar nesta luta apresentam algumas características: são portadores

20. Daniel era seu codinome utilizado no período em que participou de grupos clandestinos de guerrilha organizados contra a ditadura militar. Foi militante do movimento estudantil de Minas Gerais quando ainda era estudante de medicina. Integrou o POLOP (Política Operária), o grupo Vanguarda Popular Revolucionária (VPR), organizado pelos dissidentes do POLOP, e o Vanguarda Armada Revolucionária Palmares (VAR-PALMARES) que surge da fusão do COLINA (Comando de Libertação Nacional) com o VPR.

21. Em 2000 o Grupo Gay da Bahia apresentou uma lista com os "100 gays que abalaram o Brasil” e dentre eles cita Paulo César Bonfım, fundador do grupo GAPA/SP, e José Roberto Peruzzo Nascimento, psicólogo, atuante em defesa dos homossexuais e portador do vírus HIV, e fundador do GIV. 
do vírus, apresentam uma militância no movimento em defesa dos homossexuais, vêm de setores médios da sociedade, com formação escolar de terceiro grau, e intensa militância política.

Estes grupos participaram, ao longo dos anos 1990, de outras iniciativas em torno do ativismo da Aids, criando eventos e organizações. Destacam-se a organização de encontros nacionais de pessoas vivendo com Aids, e a criação de grupos como a Rede Nacional de Pessoas Vivendo com Aids (RNP+) e o Fórum de Ong/Aids. A ABIA e o Grupo pela Vidda participaram das iniciativas que conduziram a criação de espaços institucionais na luta contra a epidemia. Além disso, grupos como a ABIA ocuparam um lugar central neste espaço de interseção entre pesquisadores, sobretudo cientistas socais, ativistas, soropositivos e médicos, estando à frente das políticas nacionais e integrando as equipes do Programa Nacional (PARKER \& TERTO JR, 2001). São vários os casos de lideranças da $\mathrm{ABIA}$ que ocuparam cargos como consultores do Programa Nacional de Aids. A característica central destes consultores é uma articulação bem sucedida entre pesquisa na área de saúde coletiva e ciências sociais, e entre ativismo na luta contra a Aids e inserção em esferas internacionais. Nesse sentido, a instituição se tornou um espaço importante de articulação e formação de redes que conduziam a uma inserção nas políticas de Aids.

Podemos perceber que a emergência e a criação das chamadas ONGs/Aids configura uma fase da construção pública da Aids que coloca em evidência a importância da articulação entre as associações altamente qualificadas e o Estado. Se por um lado, o Estado se fortalece cooptando as lideranças, por outro, as associações ganham projeção e se tornam capazes de intervir no processo de gestão pública.

\section{Lideranças homossexuais e médicos sa- nitaristas na luta contra a Aids}

A análise das diferentes fases da constituição da Aids como um problema público permitiu identificar os atores que participam da formação desta causa e as redes de relações em que estão inseridos. Além disso, foi possivel identificar algumas situações importantes que se apresentaram para alguns protagonistas e que contribuíram para organizar suas experiências anteriores e seus contatos já estabelecidos. É por meio da relação entre lideranças do movimento homossexual, médicos sanitaristas e luta em defesa da democracia que se desenvolveu uma arena pública da Aids.

A figura 1 permite representar, graficamente, os principais atores envolvidos na organização inicial da luta contra a Aids e os grupos de origem. De forma bastante simplificada, é possível perceber as redes em que estavam inseridas as principais lideranças no momento crítico de resposta inicial à epidemia. Em pequenos círculos podemos perceber os atores, e em quadrados os movimentos sociais e profissionais a que estavam vinculados. 


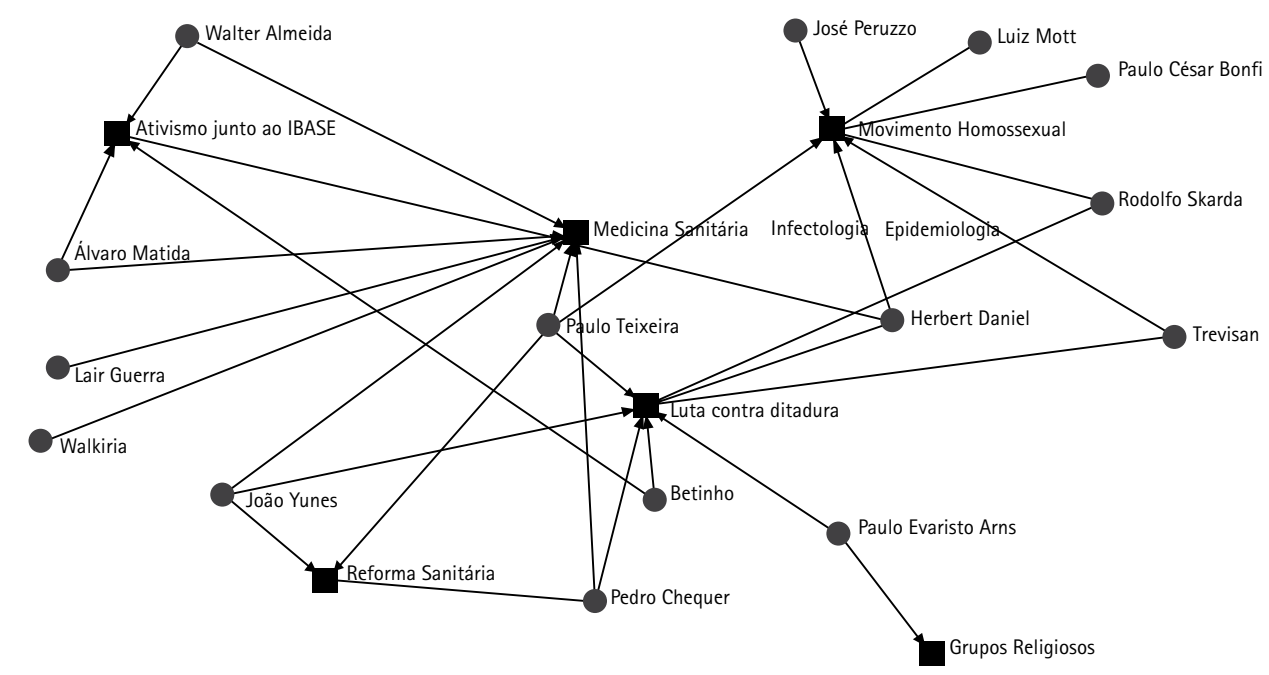

Como se percebe, o movimento de luta contra a Aids emerge de outros movimentos sociais e é fortemente marcado por uma diversidade de atores envolvidos. Além disso, estes atores sociais estavam inseridos em espaços múltiplos, o que lhes permitia compartilhar certas concepções e com isso estar exposto a mensagens e princípios ideológicos semelhantes. Dentre os grupos de origem, podemos perceber que os movimentos de luta contra a ditadura, assim como a vinculação à medicina sanitária e ao movimento homossexual são espaços em que circulam um conjunto de atores.

Este gráfico permite perceber que os principais atores reunidos em torno da problemática da Aids estavam imersos em movimentos sociais diversos, e o aparecimento da epidemia gerou uma nova situação colocando a possibilidade de uma nova forma de ativismo. Ao mesmo tempo, permite compreender que os saberes em torno da doença e as conexões que fazem entre Aids e saúde pública, por exemplo, dependem de seus investimentos acumulados anteriormente. Aqueles que investem na luta contra a Aids mobilizam os conhecimentos dos seus espaços de origem, seja por uma política de Aids, pressionando governos, lutando por uma nova concepção de saúde, seja na luta contra o preconceito e em defesa dos soropositivos. No caso dos médicos, mesmo aqueles que não estiveram vinculados ao Movimento de Reforma Sanitária, trazem uma determinada concepção de saúde que deriva dos investimentos na medicina sanitária. Esta medicina, como a epidemiologia, é considerada a área mais social da medicina, por estar vinculada, sobretudo, a uma defesa de uma medicina pública. Em suma, a identificação por parte destes atores da Aids como uma situação problemática é indissociável dos espaços de experiências dentro dos quais estes atores produzem significados e estabelecem redes de relações. 
Além disso, é preciso mencionar as especificidades regionais, uma vez que no estado do Rio de Janeiro as principais articulações estão em torno do IBASE e das redes de Betinho, e também junto ao movimento homossexual. Com o surgimento da ABIA, a qual emerge do IBASE, se reuniriam algumas das entidades vinculadas ao ativismo na luta contra a Aids, como o movimento homossexual e alguns movimentos religiosos; a ABIA reuniu médicos sanitaristas, lideranças do movimento homossexual e ativistas que se destacaram na luta contra a ditadura. Já em São Paulo, as principais articulações ocorreram pela intensa participação de lideranças do movimento homossexual e da reforma sanitária.

$\mathrm{Na}$ fase de forte mobilização, inicialmente, se destacam as organizações voltadas à temática da homossexualidade e as mobilizações do campo médico. A atuação, sobretudo dos médicos sanitaristas, e de um conjunto de profissionais da saúde, permitiu novas alianças com os ativistas. Em seguida, o aparecimento de organizações de soropositivos, o que representa um marco importante na luta política, uma vez que a soropositividade é apresentada como um elemento importante da luta contra a doença. A conversão das vítimas em ativistas experts tem sido apresentada como uma característica geral do movimento de luta contra Aids, uma vez que pode ser observada em diferentes situações nacionais ${ }^{22}$. Além disso, associada à emergência de associações de soropositivos, está o engajamento de advogados que, na luta pelos direitos dos soropositivos, se aliam aos ativistas. E, por fim, a emergência de organizações como associação de prostitutas e o movimento de mulheres que também passam a atuar na luta contra a doença.

Esta diversidade de atores está associada à própria epidemiologia da doença, uma vez que o aumento de número de casos em mulheres contaminadas com o vírus se constituiu como um dado preocupante, estimulando assim o engajamento do movimento feminista em torno da questão. Deste modo, a configuração da doença contribui para modificar os tipos de mobilização, moldando os tipos de engajamento, como já observou Epstein (1996) sobre a relação entre ciência da Aids e militância. A intensa profissionalização dos serviços, a emergência de um movimento de auto-suporte e sua articulação com o ativismo tem sido uma das marcas deste movimento.

\section{Considerações finais}

Este artigo procurou mostrar que a causa da Aids não é apenas uma causa altamente profissionalizada, mas seu processo de construção como um problema público envolveu saberes que são produto do encontro entre engajamento político e associativo e atuação profissional. Portanto, tudo que se produziu sobre a Aids até o momento é resultado desta articulação entre diferentes saberes que se mesclam. As próprias respostas médico-terapêuticas se constituem na relação com as respostas dos ativistas, não estando, portanto, dissociadas da luta política mais ampla (EPSTEIN, 1996; GALVÃO, 2000).

Para demonstrar empiricamente como isso ocorre nos apoiamos na análise da carreira do problema, o que nos permitiu compreender de onde são recrutados os ativistas e quais são as redes de relações dos quais fazem parte. Teve impacto decisivo a par- 
ticipação anterior em grupos e movimentos vinculados, sobretudo a três espaços: movimento homossexual, movimento pela reforma sanitária e grupos de contestação contra o regime militar. Vale ressaltar que o espaço de contestação contra a ditadura é a rede formal que permite conectar esses atores, uma vez que tanto aqueles que tiveram participação no ativismo homossexual quanto aqueles que tiveram um forte investimento na defesa do movimento sanitário, estavam inseridos em grupos clandestinos contra a repressão. 0 retorno de ativistas políticos exilados durante a ditadura e a própria abertura política permitiram a estes militantes reinserirem-se no espaço político nacional por meio das redes de relações construídas durante o período de forte contestação política. Isso lhes conduziu a novas formas de engajamento ${ }^{23}$.

Assim, redes formadas por este tipo de participação em grupos constituem um importante meio de acesso e entrada na luta contra a Aids. Elas têm a função de socialização que facilita um envolvimento nos movimentos sociais contribuindo de forma signifıcativa na participação individual. De acordo com Passy e Giugni (2001), as redes têm três funções determinantes: constituem estruturas de conexão que funcionam como oportunidades para participação; socializam os indivíduos nos temas de protesto; contribuem para construção da decisão de se tornar envolvido na causa. Nessa linha, as redes representam padrões de sociabilidade.

Contudo, estas redes só fazem sentido para compreendermos a luta contra a Aids se associarmos, pelo menos, a duas condições, ou situações. Primeiro, o aparecimen- to da doença e a sua situação epidêmica que, no caso da sua dinâmica no contexto brasileiro, coloca em evidência o movimento homossexual e os sanitaristas. 0 movimento homossexual foi chamado ao debate quando o tipo de vida homossexual passou a estar associado à doença e os sanitaristas constituem os primeiros profissionais da saúde a se envolverem com o caráter epidêmico da Aids. Segundo, o processo de redemocratização que coloca em evidência e cria as condições para o aparecimento de grupos e bandeiras de luta.

Os trabalhos de Epstein (1996) e Barbot (2001) sobre a gestão da epidemia em outras situações nacionais, como Estados Unidos e França, destacam que o ativismo contra a Aids se volta para o saber médico e para relação médico paciente. As principais associações, por exemplo, colocam a necessidade de acumular conhecimentos sobre as experiências individuais da doença e, com isso, modalidades de tratamento e relações diferenciadas com as famílias. Um dos principais questionamentos em jogo era o de que os médicos, que tratavam doenças como a Aids, desconheciam não só o modo de vida dos seus pacientes como as diferentes formas de perceber e viver a doença. Destaca-se a luta contra o poder e o monopólio médico e a indústria farmacêutica, observada pela atuação do Act-Up. 0 Act-Up é uma organização internacional de combate à Aids que surge em 1987, em Nova York, e se destaca por mobilizações radicais, como invasões em conferências de médicos e cientistas para discutir a questão da Aids. Assim, a luta contra a Aids é inscrita numa luta contra o poder médico

23. Uma análise detalhada sobre as trajetórias dos militantes no contexto da ditadura militar e os efeitos da contestação política na redefinição dos espaços de atuação e nas respectivas tomadas de posição, pode ser encontrada em Reis, 2007. 
e farmacêutico. E, nessa linha, os médicos clínicos, por estarem numa relação mais direta com a doença, estão mais inclinados a formar parcerias com os ativistas.

No Brasil, de início a Aids foi caracterizada como um problema de saúde pública e como tal exigia medidas governamentais imprescindiveis e urgentes. Desde o movimento homossexual, ao aparecimento das ONGs/AIDS e o investimento do setor médico - representado fortemente pela medicina sanitária - se manifestaram em busca de uma solução política que visasse à democratização do acesso à saúde e aos medicamentos. Nesse sentido, a luta contra Aids no Brasil está inscrita numa luta contra as políticas de saúde vigentes e que mobiliza tanto setores médicos, quanto movimentos sociais. 0 ativismo da Aids e a agenda ativista refletiram o engajamento crítico com as políticas de saúde pública. Enquanto que em outros países, como os Estados Unidos, o ativismo da Aids se manifestou no "engajamento crítico com a pesquisa clínica e o desejo de fazer uma ciência da Aids", como mostra Epstein (1996), no Brasil podemos perceber o intenso envolvimento com políticas de saúde e o desejo de fazer uma política da Aids. Tal característica está associada a um duplo processo: de um lado o contexto da redemocratização como uma situação que estimula determinadas formas de participação, de outro, as redes de relações dos ativistas e suas experiências anteriores contribuindo decisivamente para os contornos da luta contra a Aids no Brasil.

\section{Referências}

AVILA, C. S. Médico Sanitarista: ainda uma escolha de carreira? 1998. 123f. Dissertação (Mestrado em Saúde Pública). Fundação Oswaldo Cruz, Escola Nacional de Saúde Pública, Rio de Janeiro, 1998.

BARBOT, J. S'engager dans le monde biomédical. Diversité et front commun des associations. In: CEFAI, D. \& TROM, D. (ORG). Les formes de l'action collective. Paris: Editions de l'Ehess, 2001, p. 229-254.

BASTOS, C. Ciência, poder, acção: as respostas à Sida. Lisboa: Imprensa de Ciências Sociais, 2002.

BECKER, H. Segredos e Truques da Pesquisa. Rio de Janeiro: Zahar, 2007.

BECKER, H. Outsiders. Rio de Janeiro: Zahar, 2008.

BLUMER, H. Social Problems as Collective Behavior. Social Problems, v.18, no 3, p. 298-306, 1971.

CARRARA, S. \& MORAES, C. Um mal de folhetim? Comunicações do Iser, Rio de Janeiro, v. 4, nํำ 17, p. 20-28, 1985.

CEFAI, D.; TERZI, C. L'Expérience des Problemes Publics. Paris: Editions de L'École des Hautes Études em Sciences Sociales, 2012.

CEFAÏ, D. La construction des problèmes publics. Défınitions de situations dans des arènes publiques. Réseaux, v.14, no 75. p. 43-66, 1996.

CEFAI, D. Qu'est-ce qu'une arène publique? Quelques pistes pour une approche pragmatiste. In: CEFAÏ, D.; JOSEPH, I. (coords.). L'heritage du pragmatisme. Conflits d'urbanité et épreuves de civisme. La Tour d'Aigues: Éditions de l'Aube, 2002, p. 51-81.

COSTA, S. L. M. Aids: a construção de uma síndrome. Trabalho apresentado no XXXVI Congresso Brasileiro de Ciências da Comunicação, realizado de 04 a 07/09 de 2013.

EPSTEIN, S. Impure Science. Berkeley: University of California, 1996. 
FACCHINI, R. Sopa de Letrinhas? Movimento homossexual e produção de identidades coletivas nos anos 90. Rio de Janeiro: Garamond, 2005.

FIGARI, C. As outras cariocas: interpelações, experiências e identidades homoeróticas no Rio de Janeiro. Rio de Janeiro: IUPERJ, 2007.

FORNEL, M. Ct QUÉRÉ, L. La logique des situations. Paris: Editions EHESS, 1999.

FRANÇA, M. S. J. Política, direitos humanos e Aids: uma conversa com Paulo Roberto Teixeira. Interface: comunicação, saúde e educação, v.12, no 27, p.919-926, out./dez. 2008.

GALVÃO, J. AIDS e imprensa: um estudo de antropologia social. 1992. Rio de Janeiro: UFRJMuseu Nacional, 1992.

GALVÃO, J. AIDS no Brasil: a agenda de construção de uma epidemia. Rio de Janeiro: Editora 34, ABIA, 2000.

LANDAU, C. A Aids mudou de cara: memória coletiva e novas oportunidades para o ativismo da AIDS no Brasil. PLURAL. Revista do Programa de Pos-Graduação em Sociologia da USP, São Paulo, v. 17, no 2, p.11-44, 2011.

LOCHARD, Y; SIMONET-CUSSET M. Introduction. In: L'expert associative, le savant et le politique. Editions Syllepse,p. 7-14, 2003.

LENOIR, R.. Objeto sociológico e problema social. In: CHAMPAGNE, P. et al. Iniciação à prática sociológica, Petrópolis: Vozes, 1998, p. 59-106.

MATHIEU, L. L'espace des mouvements sociaux. Broissieux: Croquant, 2012.

NASCIMENTO, D. R. Aids: um desafio à cidadania no final do século. In VI CONGRESSO LUSO-AFRO -BRASILEIRO. Porto, 2000. Anais do VI Congresso Luso Afro-brasilerio, 2000.

PARKER; TERTO JR. Solidariedade: a ABIA na virada do milênio. Rio de Janeiro: Publicações da ABIA, 2001.

PASSY, F.; GIUGNI, M. Social Networks and Individual Perceptions: explaining differential partici- pation in social movements. Sociological Forum, v.l. 16, no 1, p. 123-153, 2001.

PETRARCA, F. R. O Jornalismo como profissão: recursos sociais, titulação acadêmica e inserção profissional dos jornalistas no Rio Grande do Sul. 2001. 308f. Tese (Doutorado em Sociologia). Programa de Pós-Graduação em Sociologia, UFRGS, Porto Alegre, 2007.

PETRARCA, F. R. Atuação profissional e engajamento militante na defesa de causas sociais no estado de Sergipe. Relatório de Pesquisa Final CNPq. 50f. 2012.

POLLAK, M. Os Homossexuais e a Aids: sociologia de uma epidemia. São Paulo: Liberdade. 1990.

REIS, E. T. Contestação, engajamento e militantismo: da "luta contra a ditadura" à diversificação das modalidades de intervenção política no Rio Grande do Sul. Tese (Doutorado em Ciência Política). 330f. Programa de Pós-Graduação em Ciência Política- UFRGS, 2007.

SNOW, D.; EKLAND-OLSO; ZURCKER Jr. Social networks and social movements: a microstructural approach to differential recruitment. American Sociological Review. v. 45 (October): p. 787-801, out.1980.

SOPHIA, D. C. O CEBES e o movimento de reforma sanitária: história, política e saúde pública (Rio de Janeiro, 1970-1980). 2012. $216 f$. Tese (Doutorado em Saúde Pública). Programa de Pós- Graduação em História das Ciências e da Saúde da Casa de Oswaldo Cruz/Fiocruz, 2012.

SPECTOR, M.; KITSUSE, J. Sociologie des problèmes sociaux: un modele d'historie naturalle. In: CEFAI, D.; TERZI, C. L'Expérience des Problèmes Publics. Paris: Editions de L'École des Hautes Études en Sciences Sociales, 2012, p. 81-108. 
RESUMO

Este artigo analisa o processo de formação de uma coletividade em torno da problemática da Aids, no cenário nacional brasileiro, com o objetivo de identificar os atores envolvidos nas respostas iniciais à epidemia, o contexto no qual estavam inseridos e as redes de relações das quais faziam parte. Uma das principais conclusões do trabalho é a de que os atores que participaram da formação de uma arena pública em torno da Aids, apesar de pertencerem a diferentes movimentos, possuíam fortes ligações entre si e estavam imersos em redes de relações que os aproximavam. Tais redes eram oriundas, sobretudo, de três espaços: movimento homossexual, movimento pela reforma sanitária e grupos de contestação contra o regime militar. Com base nisso, foi possivel verificar ainda que a luta contra a Aids no Brasil está inscrita numa luta contra as políticas de saúde vigentes, que mobiliza tanto setores médicos, quanto movimentos sociais.

\section{PALAVRAS-CHAVE}

Problemas públicos. Aids. Engajamento.

\section{ABSTRACT}

This article analyzes the process of forming a community around the issue of AIDS in the Brazilian national scene, in order to identify: the actors involved in the early responses to the epidemic, the context in which they were inserted and the networks of relationships which were part. One of the main conclusions is that the actors who participated in the formation of a public arena about Aids had strong links with each other and were immersed in networks of relationships that approached. These networks were connected to three spaces: the homosexual movement, movement for health reform and protest groups against the military regime.In addition, the fight against AIDS in Brazil is entered in a fight against the current health policies and mobilizing both medical sectors, as social movements.

\section{KEYWORDS}

Public problems. SIDA. Commitment. 